\title{
Misbruk av gammahydroksybutyrat
}

\author{
Sammendrag \\ Bakgrunn. Gammahydroksybutyrat \\ (GHB) er en kroppsegen substans som \\ kan brukes som rusmiddel. Informa- \\ sjon fra flere kilder tyder både økende \\ tilgjengelighet og bruk i Norge. Det er \\ også rapportert tiltakende bruk av den \\ kjemiske forløperen gammabutyrolak- \\ ton (GBL).
}

\begin{abstract}
Materiale og metode. Artikkelen er basert på et skjønnsmessig utvalg av artikler etter litteraturs $ø$ k i PubMed samt på rapporter fra norske og europeiske myndigheter og forskningsinstitutter.
\end{abstract}

Resultater. Inntak av lavere doser GHB gir rus, mens høyere doser kan gi forgiftninger. Dødsfall er beskrevet. Effekten kan være varierende, på grunn av en bratt dose-respons-kurve og interaksjon med alkohol og andre rusmidler. Behandlingen av forgiftninger er symptomatisk og støttende. Behandling av abstinenser er også støttende, men delirium kan behandles som ved delirium tremens.

Fortolkning. Det er etter vår vurdering behov for mer informasjon om GHBmisbruk til helsepersonell samt forebyggende tiltak rettet spesifikt mot potensielle brukergrupper.

\author{
Jørgen G. Bramness \\ j.g.bramness@medisin.uio.no \\ Senter for rus og avhengighetsforskning \\ Universitetet i Oslo \\ og \\ Avdeling for legemiddelepidemiologi \\ Nasjonalt folkehelseinstitutt \\ Siren Haugland \\ Uni Helse \\ Uni Research AS \\ Bergen
}

Gammahydroksybutyrat (GHB) ble først syntetisert i 1960 (1). Det ble senere oppdaget at stoffet finnes naturlig i svært lave nivåer i kroppen, med en økt mengde hos gravide (2). GHB kan under visse omstendigheter dannes i prøver som er tatt ved obduksjon (3). GHB har tidligere vært brukt som anestesi- og sovemiddel, og til behandling av depresjon. Det markedsføres for behandling av narkolepsi under navnet Xyrem, også i Norge, og som et hjelpemiddel ved opiat- og alkoholavvenning under navnet Alcover i Østerrike og Italia.

Den ikke-medisinske bruken startet i kroppsbyggermiljøene i 1980-årene på grunn av mulig anabol og sentralstimulerende virkning. I 1990-årene dukket GHB opp på utelivsscenen under det misvisende navnet flytende ecstasy. Det oppsto en bekymring for helserisikoen, spesielt fordi det var mistanke om at GHB ble tilsatt drinker, for å gjøre det lettere å foreta seksuelle overgrep. Relativt nylig er det også rapportert om inntak av den kjemiske forløperen gammabutyrolakton(GBL), som raskt omdannes til GHB i kroppen (fig 1). På grunn av kontrolltiltak er det blitt vanskeligere å få tak i GHB, men det er nokså enkelt å fremstille GHB fra GBL og forløperen 1,4 butandiol (1,4-BD), som begge brukes i kjemisk industri og er kommersielt tilgjengelige.

Bedret tilgang og økende forbruk har styrket ønsket om målrettede tiltak. I denne artikkelen gir vi en oversikt over symptomer ved bruk av GHB. I tillegg er det et mål å gi informasjon om behandling og forebygging av forgiftninger, abstinens og avhengighet.

\section{Materiale og metode}

Denne oversikten er basert på et skjønnsmessig utvalg av artikler og rapporter. Ved litteratursøk i PubMed ble følgende søkeord brukt: «gammahydroksybutyrat», «GHB», «gammabutyrolakton» og «GBL», kombinert med søkeordene «pharmacology», «use», «abuse», «addiction», dependence», «intoxications», «treatment» og «prevention». Det ble særlig lett etter oversiktsartikler. Videre har vi lagt til grunn statistikk fra norske myndigheter $(4,5)$, undersøkelser fra norske forskningsinstitusjoner (6-9) samt en spesialrapport om GHB/GBL fra europeiske narkotikaovervåkingsmyndigheter (10).

\section{Forekomst av GHB-misbruk}

Til tross for en relativt begrenset tilgjengelighet og et lavt misbruk av GHB, viser statistikk fra Kripos en økning i antall og volum av norske GHB-beslag fra 2007 (6). GHB er nå beslaglagt i de fleste av landets politidistrikter. I 2007 rapporterte norsk politi om en illegal «fabrikk» for fremstilling av GHB. GHB/ GBL utgjorde 1,7\% av alle beslag i 2009.

I en undersøkelse fra Statens institutt for rusmiddelforskning i 2008, rapporterte under $1 \%$ av norsk ungdom mellom $15-20$ år at de hadde prøvd GHB. Dette er i tråd med resultater fra undersøkelser i 2007 blant 15-16åringer i 35 europeiske land, dette dreier seg i hovedsak om unge som også misbruker andre illegale rusmidler (4). Andre internasjonale studier viser at forbruket i visse miljøer kan være betydelig høyere. Dette er vist i undersøkelser både fra ravemiljøet og klubber for homofile (11). Vi kjenner ikke slike tall fra Norge, men det finnes rapporterer om GHB-overdoser i forbindelse med konserter.

I de halvårlige kartleggingsundersøkelsene «Føre var» $\mathrm{i}$ Bergen ble det i perioden 2008-10 registrert et økende forbruk av GHB (12). Nasjonalt folkehelseinstitutt registrerte også en økende forekomst av GHB hos påvirkede bilførere første halvdel av år 2000 (7). Ved Oslo universitetssykehus var $7 \%$ av akuttforgiftningene med påfølgende innleggelse GHB-forgiftninger i perioden 2003-04, bare benzodiazepiner, alkohol, paracetamol og opioider var årsak til en høyere andel akuttinnleggelser (13).

\section{Hovedbudskap}

- Bruken av gammahydroksybutyrat (GHB) og gammabutyrolakton (GBL) er antakelig økende

- GHB har en bratt dose-respons-kurve, og potenseres av legemidler og andre rusmidler

- Behandlingen av forgiftninger er symptomatisk og støttende

- Forebyggende tiltak bør være målrettet 


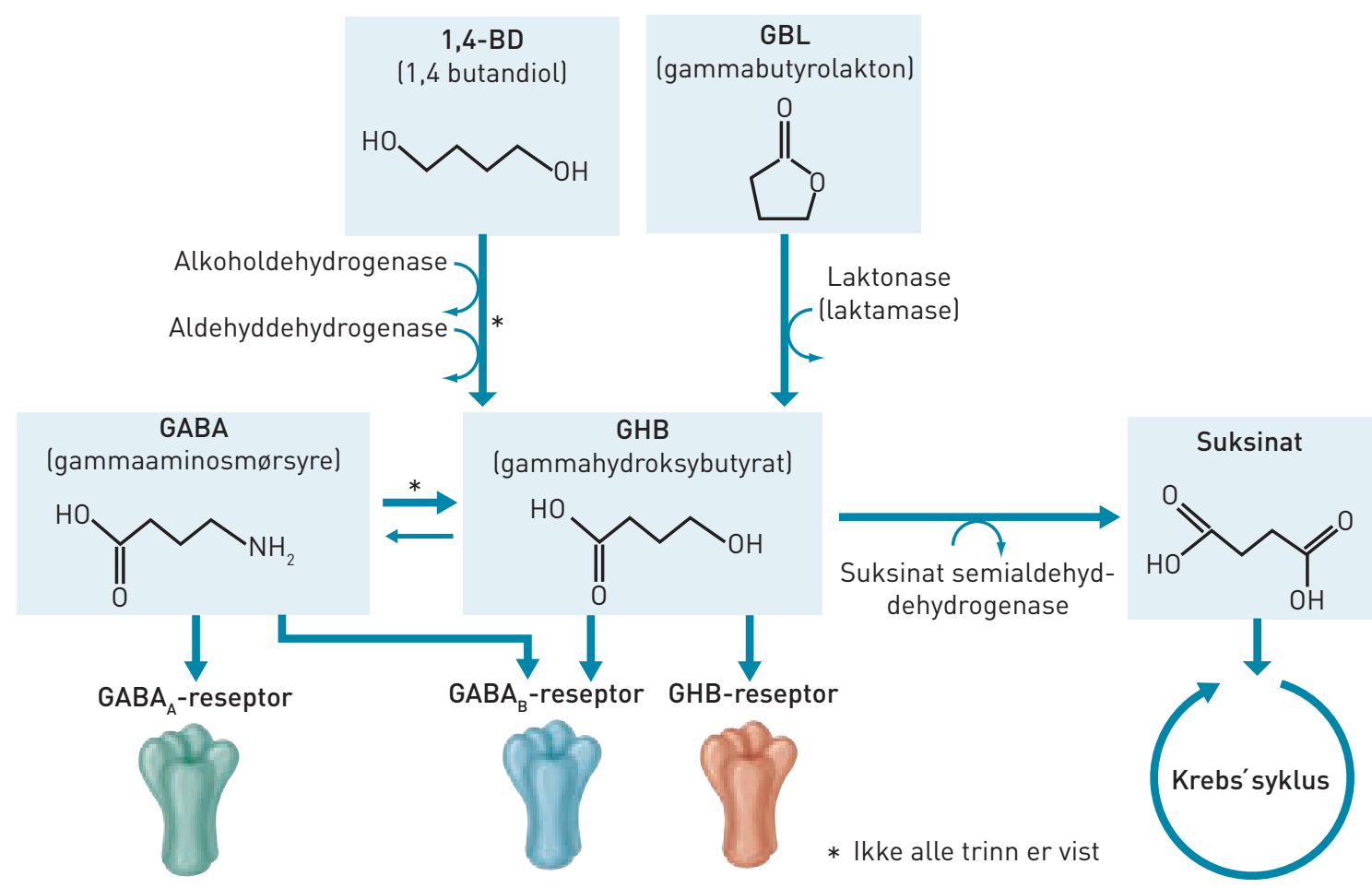

Figur 1 Gammabutyrolakton (GBL) og 1,4-BD omdannes i kroppen til gammahydroksybutyrat (GHB). GHB kan påvirke GABA $A_{B}$-reseptoren og antakelig en egen GHB-reseptor. GHB står i likevekt med gammaaminosmørsyre (GABA). GHB brytes bl.a. ned via Krebs' syklus

\section{Farmakologi, bruksmønster og effekter}

Man kjenner ikke fullstendig farmakologien til GHB. Til tross for at det er en gammaaminosmørsyre (GABA)-analog, virker den antakelig ikke direkte over $\mathrm{GABA}_{\mathrm{A}}$-reseptorkomplekset. GHB er trolig en agonist til $\mathrm{GABA}_{\mathrm{B}}$-reseptoren (som baklofen) og en egen GHB-reseptor (fig 1). Man kjenner ikke fullstendig hva effekten på $\mathrm{GABA}_{\mathrm{B}}{ }^{-}$ reseptoren innebærer, men det gir antakelig sentral dempning uten rusopplevelse. GHB kan også omdannes til GABA i kroppen og derigjennom virke på $\mathrm{GABA}_{\mathrm{A}}$-reseptoren og gi ytterligere sentralnervøs dempning og en rusopplevelse. I høyere doser virker GHB trolig også inn på andre monoaminerge nevrotransmittersystemer (dopamin, serotonin og noradrenalin).

GHB tas raskt opp fra mage-tarm-kanalen og passerer hurtig over blod-hjerne-barrieren. Virkningen kommer omtrent 15 minutter etter inntak og varer 2-4 timer. Den terminale halveringstiden $\left(T_{1 / 2}\right)$ er omtrent en halv time. Denne korte halveringstiden gjør at det sjelden påvises GHB i blodprøver. Det metaboliseres til stoffer som ikke lar seg spore (fig 1), men ca. $5 \%$ utskilles uomdannet i urinen, noe som gjør at det kan oppdages ved kromatografiske metoder i 3-10 timer etter inntak. GHB spores ikke ved semikvantitative immunologiske metoder (urinstiks).

Doseringen av GHB kan som for mange illegale midler være litt tilfeldig. Vanlig dosering er tre teskjeer eller «en kork» med GHB (6). Dette tilsvarer vanligvis et inntak på 0,5-2 gram. Latenstid før effekt kan føre til at brukeren tar en ny dose før virkningen av en tidligere dose inntrer. Man har trodd at mesteparten av bruken har vært enkeltinntak eller inntak over noen timer, men noen velger å innta stoffet flere ganger i døgnet over tid, gjerne dosert ved hjelp av en tåteflaske for å opprettholde rusen. Slik bruk over tid øker faren for å utvikle avhengighet $(14,15)$. Anslagene over andelen brukere som blir avhengige av GHB, er angitt å være fra $4 \%$ (16) til $21 \%(17)$.

Inntak av lave doser GHB kan gi en effekt som minner om alkoholrus. Dette inkluderer en initial oppstemthet (eufori), hemningsløsende effekt, og en opplevelse av å komme lettere i kontakt med andre. Økt libido og en endaktogen effekt er rapportert. Mange opplever en beroligende og anxiolytisk effekt. Høyere doser gir også rus, men en økende dempning. På grunn av stoffets bratte dose-respons-kurve er virkningen svært uforutsigbar.

\section{Akutte GHB-forgiftninger}

Symptomene ved GHB-forgiftning likner forgiftninger etter inntak av andre sentralnervøst dempende midler (18). Symptomer som svimmelhet, forvirring, plutselig inntreffende søvn, ufrivillig vannlating, kvalme og oppkast er vanlige. Man kan også se bradykardi og svekket respirasjon. Vertikal nystagmus, epileptiske anfall, oppkast, mild hypotermi og ataksi, dystonier og muskelspasmer er rapportert $\mathrm{i}$ alvorlige tilfeller (15-17). Pasienter kan også komme til skade som følge av akutt innsettende muskulær hy- potoni. Bevisstløshet er heller ikke uvanlig $(5,17,19-22)$. I intervjuer beskriver rusmiddelbrukere dette som å 'stemple ut', og det er trolig langt fra alle disse som får kontakt med helsevesenet (23). I de fleste tilfeller våkner pasientene spontant i løpet av 1,5-3 timer (19-21, 24). Det finnes også rapporter om ekstrem agitasjon ved oppvåkning $(17,19)$. Andre dempende rusmidler som alkohol, opioider, cannabis og benzodiazepiner vil kunne forsterke virkningen av GHB, og øke faren for forgiftninger (25). Det er flere rapporter om dødsfall hos personer som ikke kommer til behandling, og som «sovner» inn etter å ha blitt liggende uten oppfølging. Hjertestans og respirasjonssvikt er oftest registrert som dødsårsak i disse tilfellene (25).

Antagonister som flumazenil og nalokson er forsøkt $\mathrm{i}$ behandling av forgiftninger, men har på grunn av den korte terminale halveringstiden til GHB begrenset eller ingen effekt. På grunn av den raske absorpsjonen av GHB i mage-tarm kanalen har ventrikkelskylling og administrering av aktivt kull liten nytte. Behandling av forgiftninger skal derfor i stor grad være støttende. Noen ganger brukes intubering med mekanisk ventilasjon, spesielt for å beskytte luftveiene hvis pasienten kaster opp (26-28).

\section{GHB-abstinens}

Symptomene på abstinens etter langvarig bruk av GHB kan komme kort tid (1-6 timer) etter siste inntak. Symptomene er dem man ser ved redusert GABA-aktivitet $(29,30)$, som ved abstinens etter alkohol, 
benzodiazepiner og barbiturater, og skyldes antakelig en nedregulering av reseptormedierte effekter. Dette kan innebære kvalme og oppkast, angst, takykardi, hypertensjon, tremor og svetting, søvnløshet, psykomotorisk uro og sug etter mer $\operatorname{GHB}(14,16,20)$. Symptomene vil være selvbegrensende hos en del pasienter, men kan også utvikle seg til fullt delirium med hallusinasjoner, vrangforestillinger og død (14, 16, 22, 29, 31-33). Rabdomyolyse og epileptiske anfall er blitt rapportert (29). De viktigste differensialdiagnosene for GHB abstinenssyndrom er abstinens/delirium etter alkohol- eller benzodiazepinbruk, men disse kommer gjerne noe senere i forhold til siste inntak av rusmidler. Andre viktige differensialdiagnoser er malignt nevroleptikasyndrom, delirium forårsaket av en somatisk tilstand eller serotonergt syndrom. Forløpet av GHB-abstinens kan være overraskende protrahert sett på bakgrunn av stoffets korte terminale halveringstid $\left(\mathrm{T}_{1 / 2}\right)$, med progrediering av symptomer de første 4-6 dagene, og avtakende symptomer de påfølgende dagene. Tilbakefall av symptomer i den andre uken er beskrevet (34), men mekanismene for dette er ikke fullstendig kjent.

Behandling av GHB-abstinens er ikke systematisk undersøkt. Alvorlige tilfeller krever innleggelse i sykehus, for overvåking av vitale funksjoner og igangsetting av støttende tiltak, samt sedasjon for å motvirke agitasjon. Delirium og tilstander som nærmer seg dette, behandles med høye doser benzodiazepiner, som ved delirium etter seponering av alkohol eller benzodiazepiner $(8,29,31,32)$. Antipsykotiske legemidler er antakelig ikke effektive og kan forårsake bivirkninger som dystoni og redusert krampeterskel $(32,33,35)$, men olanzapin er beskrevet som nyttig i én kasus-rapport (36). Hos enkelte pasienter med benzodiazepinrefraktært delirium kan det være hensiktsmessig med et tillegg av barbiturater. Baklofen, som er en $\mathrm{GABA}_{\mathrm{B}}$-reseptoragonist har gitt gunstig effekt ved abstinensbehandling $\mathrm{i}$ noen pasientstudier (37). Behandling av abstinens og avhengighet kompliseres av høy forekomst av blandingsmisbruk. Den potenserende effekten av legemidler kan også være et problem etter utskrivning fra sykehus. Om pasienten har fått symptomatisk behandling med benzodiasepiner med lang halveringstid, kan GHB-inntak kort tid etter forårsake respirasjonsstans (32).

\section{Forebygging}

Forebyggende og skadereduserende tiltak i forbindelse med bruk av GHB/GBL har vært gjennomført som nasjonale og lokale prosjekter i en rekke land. Tiltakene har vanligvis som mål å lære opp ansatte på utesteder og spre informasjon om risiko ved bruk (10). I Norge har vi ikke iverksatt systematiske tiltak for å forebygge bruk av GHB. De senere år er det likevel gitt noe informasjon om GHB som rusmiddel, blant annet fra Folkehelseinstituttet og gjennom intervjuer med helsepersonell i mediene (7). I andre land har det vært gjennomført tiltak via Internett, med informasjon om forebygging eller skadereduksjon ved bruk av GHB/GBL. De fleste nettstedene har rusbrukere som målgruppe, særlig de som deltar på rave- og teknoarrangementer. Flertallet av nettstedene har vært lokalisert i Storbritannia, Nederland, Spania, Tyskland og Frankrike (10).

I de samme landene har utelivsbransjen arbeidet for å hindre GHB-bruk og overdoser, og samarbeidet med helsepersonell om førstehjelp og innleggelse ved mistanke om overdose. En spesialrapport om GHB/GBL fra europeiske narkotikaovervåkingsmyndigheter omhandler eksempler på tiltak i flere land (10). Disse har vært plakater på utesteder, vakthold med førstehjelpskompetanse og tekniske hjelpemidler som skal hindre tilsetting i drikkevarer. I Paris ble et «nattklubb-charter» utarbeidet gjennom prosjektet Fêtez clairs (/www.fetez-clairs.org/ (30.6. 2011)). Dette ble underskrevet av ledelsen $\mathrm{i}$ flere nattklubber for å redusere inntaket av narkotika i deres lokaler. I Paris

Tabell 1 Noen resultater fra kartlegging om gammahydroksybutyrat (GHB)/ gammabutyrolak ton (GBL) i Bergen, 2010 (23)

Informasjon fra brukere

GHB/GBL selges først og fremst gjennom nettverk, med tett kobling til salg av sentral-

stimulerende midler som amfetamin og metamfetamin

$\mathrm{GHB} / \mathrm{GBL}$ gir billigere rus enn alkohol

Det å sovne etter GHB inntak vurderes ikke som overdose

Hvem er brukerne?

Unge voksne amfetaminbrukere som supplerer med GHB/GBL

Ungdom og voksne som sporadisk bruker GHB/GBL i festsammenheng, kan ha eksperimenterende holdning til illegale rusmidler

Etablerte opiatbrukere med sannsynlig tilknytning til det åpne rusmiljøet, hvor GHB/GBL er relativt nytt

Informasjon fra politi, helsepersonell og andre hjelpetjenester

Opplever mangel på oppdatert og kvalitetssikret informasjon

Lovgivningen på området oppleves som et problem

Behov for retningslinjer for akuttbehandling av GHB/GBL-forgiftninger

finnes også Les nuits claires (www. lesnuitsclaires.fr/compagnie les nuits claires/ Bienvenidos.html (30.6 2011)), et samarbeid mellom byens administrasjon, politiet, forebyggende organisasjoner, nattklubber og en lokalradio. I prosjektet inngår opplæring av ansatte på utesteder og informasjon om GHB/GBL. Byrådet i Paris har også finansiert en plakat om risiko ved bruk av GHB som er slått opp på utesteder. I London har en informasjonskampanje om GHB vært ledet av politiet og en veldedig organisasjon. Heftet «Safer clubbing» gir informasjon om helse og sikkerhet ved dansearrangementer, og anbefaler at klubbene har førstehjelpspersonell som kan håndtere akuttsituasjoner i forbindelse med narkotikabruk (www.healthpromotionagency.org.uk/work/ drugs/campaigns 1.htm (30.6.2011)). I Tyskland har det vært et samarbeid mellom flere helseorganisasjoner om en plakat som advarer mot farene ved GHB-overdose. I Nederland informerer de nasjonale Clubs and Drugs-prosjektene om GHB/GBL til brukere av partydop, og gir også opplæring til ansatte på utestedene. I disse prosjektene har det også vært fokus på å beskytte gjestene mot ufrivillig inntak av GBH, gjennom såkalt «drink spiking» og seksuelle overgrep som følge av inntak. Det er ikke foretatt en forskningsmessig evaluering av informasjonen og tiltakene i utelivsbransjen. Effekten av tiltakene er derfor usikker.

Det best dokumenterte tiltaket har vært samarbeid mellom flere land for å endre lovgivingen (10). Da GHB fikk narkotikastatus i 2000, ble det registrert en umiddelbar reduksjon i det åpne salget av GHB på nettet. Videre har både EU og andre land begrenset muligheten til å importere forløperne til GHB. GBL og 1,4-BD ble klassifisert som narkotika i Norge i mars 2010. Denne lovendringen er ikke minst viktig for å redusere mulighetene for å fremstille GHB lokalt, noe som er antatt å begrense tilgjengeligheten for uerfarne brukere med liten kontroll over dosering og toksisitet.

Et viktig utgangspunkt for forebyggende tiltak er kunnskap om brukerne, og omfanget av bruk (23). I 2010 samarbeidet Kompetansesenteret Rus - Region Vest ved Stiftelsen Bergensklinikkene og Utekontakten i Bergen om en kartlegging blant brukere, helsepersonell, politi og andre hjelpetjenester (23) (tab 1). Resultatene var i samsvar med funn fra andre undersøkelser $(9,10,38)$, og tyder på økende tilgjengelighet og regelmessig misbruk knyttet til eksisterende rusmiljøer, men ikke utstrakt bruk i store ungdomsgrupper. Utenfor belastede rusmiljøer ble det funnet mer sporadisk bruk, knyttet til misbruk av andre rusmidler. Flertallet av brukerne er trolig 18-35 år. I handlingsplanen som fulgte rapporten er det foreslått en rekke tiltak, blant annet informasjon til mediene, foreldre, fagpersoner og myndigheter, og kontakt med kjente og potensielle brukere. I tillegg er det forslag til planer for behandling, og vurde- 
ring av tilgjengelighet, forekomst og behandlingseffekt. Det er ønskelig at disse og andre tiltak kan evalueres forskningsmessig.

\section{Konklusjon}

Det ser ut til at GHB-misbruk er økende i Norge, og at også forløperen GBL benyttes som rusmiddel. Misbruket er først og fremst knyttet til eksisterende rusmiljøer, men forekommer også i andre grupper. Selv om bruken av GHB fortsatt er lite utbredt, er de helsemessige konsekvensene betydelige for dem det gjelder. Etter vår oppfatning er det derfor behov for økt informasjon om GHB til helsepersonell og til risikogrupper.

\section{Jørgen G. Bramness (f. 1962)}

er professor og forskningsdirektør ved Senter for rus og avhengighetsforskning (SERAF) ved Universitetet i Oslo og seniorforsker ved Avdeling for legemiddelepidemiologi ved Nasjonalt folkehelseinstitutt.

Ingen oppgitte interessekonflikter.

\section{Siren Haugland (f. 1961)}

er dr.med., forskningsleder ved Uni helse, Uni Research AS. Hun er fastlege, og skolelege i videregående skole.

Ingen oppgitte interessekonflikter.

\section{Litteratur}

1. Laborit H. Sodium 4-hydroxybutyrate. Int J Neuropharmacol 1964; 3: 432-41.

2. Nordmo E. Gravide har mer GHB i urin. Troms $\varnothing$ RELIS Nord-Norge, 2010

3. Bessman SP, Fishbein WN. Gamma-hydroxybutyrate, a normal brain metabolite. Nature 1963; 200 1207-8.

4. Hibell B, Guttormsson U, Ahlström S et al. The 2007 ESPAD Report - substance use among stu dents in 35 European countries. Stockholm Espad, 2009.

5. Galloway GP, Frederick SL, Staggers FE jr. et al. Gamma-hydroxybutyrate: an emerging drug of abuse that causes physical dependence. Addiction 1997; 92: 89-96.
6. KRIPOS Narkotika- og dopingstatistikk 2009 Dslo: KRIPOS, 2009

7. Al-Samarraie MS, Karinen R, Mørland J et al. Blood GHB concentrations and results of medical examinations in 25 car drivers in Norway. Eur $J$ Clin Pharmacol 2010; 66: 987-98.

8. Helland A, Skjøtskift S. Medikamentell behandling av alkoholabstinens. Tidsskr Nor Legeforen 2008; 128: $1182-4$.

9. Hordvin, 0 , red. The drug situation in Norway 2010 Annual report to the European Monitoring Centre for Drugs and Drug Addiction - EMCDDA. Rapport. Oslo: Statens institutt for rusmiddlforskning. (2010)

10. Hillebrand J, Olszewski D, Sedefov R. GHB and its precursor GBL: an emerging trend case study. Lisboa: EMCDDA, 2008

11. Ramo DE, Grov C, Delucchi K et al. Typology of club drug use among young adults recruited using time-space sampling. Drug Alcohol Depend 2010; 107: 119-27.

12. Føre-Var rapporten juni 2010: Rustrender i Bergen. Bergen: Bergensklinikkene, 2010.

13. Hovda KE, Bjornaas MA, Skog K et al. Acute poisonings treated in hospitals in Oslo: a one-year prospective study (I): pattern of poisoning. Clin Toxico (Phila) 2008; 46: 35-41.

14. McDaniel CH, Miotto KA. Gamma hydroxybutyrate (GHB) and gamma butyrolactone (GBL) withdrawal: five case studies. J Psychoactive Drugs 2001; 33: 143-9

15. Degenhardt L, Darke S, Dillon P. GHB use among Australians: characteristics, use patterns and associated harm. Drug Alcohol Depend 2002; 67: $89-94$

16. Li J, Stokes SA, Woeckener A. A tale of novel intoxication: a review of the effects of gammahydroxybutyric acid with recommendations for management. Ann Emerg Med 1998; 31: 729-36.

17. Miotto K, Darakjian J, Basch J et al. Gammahydroxybutyric acid: patterns of use, effects and withdrawal. Am J Addict 2001: 10: 232-41.

18. GHB. Oslo: Giftinformasjonen, 2007.

19. Chin RL, Sporer KA, Cullison B et al. Clinical course of gamma-hydroxybutyrate overdose. Ann Emerg Med 1998: 31: 716-22

20. Craig K, Gomez HF, McManus JL et al. Severe gamma-hydroxybutyrate withdrawal: a case repor and literature review. J Emerg Med 2000; 18: $65-70$.

21. Thomas $G$, Bonner S, Gascoigne A. Coma induced by abuse of gamma-hydroxybutyrate $[\mathrm{GBH}$ or liquid ecstasyl: a case report. BMJ 1997; 314 $35-6$.

22. Nicholson KL, Balster RL. GHB: a new and novel drug of abuse. Drug Alcohol Depend 2001; 63: $1-22$

23. Grung M. GHB/GBL. Kartleggingsrapport i Bergen og omegn 2010. Bergen: Utekontakten i Bergen,
Bergen Kommune, Stiftelsen Bergensklinikkene 2010

24. Mason PE, Kerns WP 2nd. Gamma hydroxybutyric acid (GHB) intoxication. Acad Emerg Med 2002; 9: $730-9$

25. Zvosec DL, Smith SW, Porrata T et al. Case series of $226 \gamma$-hydroxybutyrate-associated deaths: letha toxicity and trauma. Am J Emerg Med 2011; 29 : 319-32

26. Kam PC, Yoong FF. Gamma-hydroxybutyric acid: an emerging recreational drug. Anaesthesia 1998, 53: $1195-8$

27. Drasbek KR, Christensen J, Jensen K. Gammahydroxybutyrate-a drug of abuse. Acta Neurol Scand 2006; 114: 145-56.

28. Mason PE, Kerns WP 2nd. Gamma hydroxybutyric acid (GHB) intoxication. Acad Emerg Med 2002; 9 $730-9$.

29. Wojtowicz JM, Yarema MC, Wax PM. Withdrawal from gamma-hydroxybutyrate, 1,4-butanediol and gamma-butyrolactone: a case report and systematic review. CJEM 2008; 10: 69-74.

30. Dyer JE, Roth B, Hyma BA. Gamma-hydroxybutyrate withdrawal syndrome. Ann Emerg Med 2001. 37: 147-53.

31. Snead OC 3rd, Gibson KM. Gamma-hydroxybutyric acid. N Engl J Med 2005: 352: 2721-32.

32. McDonough M, Kennedy N Glasper A et al. Clinical features and management of gamma-hydroxybutyrate (GHB) withdrawal: a review. Drug Alcohol Depend 2004; 75: 3-9

33. Tarabar AF, Nelson LS. The gamma-hydroxybutyrate withdrawal syndrome. Toxicol Rev 2004; 23 : 45-9.

34. Gonzalez A, Nutt DJ. Gamma hydroxy butyrate abuse and dependency. J Psychopharmacol 2005 19: 195-204

35. Rosenberg MH, Deerfield LJ, Baruch EM. Two cases of severe gamma-hydroxybutyrate withdrawal delirium on a psychiatric unit: recommendations for management. Am J Drug Alcohol Abuse 2003: 29: 487-96.

36. Bennett WR, Wilson LG, Roy-Byrne PP. Gammahydroxybutyric acid (GHB) withdrawal: a case report. J Psychoactive Drugs 2007; 39: 293-6.

37. LeTourneau JL, Hagg DS, Smith SM. Baclofen and gamma-hydroxybutyrate withdrawal. Neurocrit Care 2008; 8: 430-3.

38. Waal H, Clausen T, Håseth A et al. (2010). Statusrapport 2009. Senter for rus og avhengighetsforskning. Rapport 1/2010. Universitetet i Oslo.

Mottatt 3.1. 2011, første revisjon innsendt 10.5. 2011, godkjent 7.7. 2011. Medisinsk redaktør Jon Amund Kyte. 